\title{
El paraíso perdido: La adaptación a la pantalla de Las viudas de los jueves
}

\author{
Thomas Deveny \\ McDaniel College
}

tdeveny@mcdaniel.edu

\begin{abstract}
In 2005, Claudia Piñeiro published Las viudas de los jueves, a novel about the life in "countries" (gated neighborhoods) in the greater Buenos Aires, and in 2009, Marcelo Piñeyro adapted it to the screen. Athough Mavi, a real estate agent, describes life there as a paradise, we see that problems and hypocrisy dominate throughout the film. Piñeyro utilizes various cinematographic techniques to underscore the economic dichotomy between the "inside" and the "outside" and to emphasize the themes of sex and death. Dudley Andrew emphasizes the importance of "the sociology and aesthetics of adaptation," and Piñeyro's film, just like the original novel, reflects what sociological studies by Svampa and Castelo reveal about life in the "countries." In addition, the film is made in a moment in which Argentina's economic problems continue. Although Piñeiro's work is not a detective novel, the structure of the two texts
\end{abstract}


have elements in common with that genre. Although the film version does not have the moral weight of the original narrative, the film makes us see that life in the "countries" can be paradise lost.

Keywords: Film adaptation; Countries; economic divisions

\section{Resumen}

En 2005, Claudia Piñeiro publica Las viudas de los jueves sobre la vida en los countries (barrios privados) del Gran Buenos Aires, y en 2009, Marcelo Piñeyro la adapta a la pantalla. Aunque Mavi, una agente inmobiliaria, describe la vida allí como un paraíso, a lo largo de la película vemos que lo que predomina son los problemas y la hipocresía. Piñeyro utiliza varias técnicas cinematográficas para destacar la dicotomía económica entre "adentro" y "afuera" y hacer hincapié en los temas del sexo y de la muerte. Dudley Andrew destaca la importancia de "the sociology and aesthetics of adaptation" y la película de Piñeyro, tanto como la novela original, refleja lo que los estudios sociológicos de Svampa y Castelo revelan sobre la vida de los countries. Además, el film se rueda en un momento en que continúan los problemas económicos argentinos. Aunque la obra de Piñeiro no es una novela negra, la estructura de los dos textos tiene elementos en común con la novela de detectives. Aunque el final de la versión fílmica no tiene el peso moral de la versión original, la película nos hace ver el paraíso perdido que es la vida en los countries.

Palabras clave: adaptación cinematográfica; countries; divisiones socioeconómicas

$\mathbf{E}^{2}$ la Argentina, los countries son los barrios privados y cercados localizados en el campo y son lugares de residencia para las clases altas del país. Como observa Laura Elina Raso, “La adopción del brutal modelo del neoliberalismo en la Argentina en los años 90 trajo aparejadas consecuencias no sólo económicas... sino también el aumento de las desigualdades sociales y la 
construcción discursiva de sujetos 'exitosos' o 'perdedores.' La emergencia de urbanizaciones privadas fue uno de los síntomas de esta década" (25). En sus estudios acerca de los countries, la socióloga Maristella Svampa opina: "Es innegable que este nuevo patrón socioespacial participa de la expansión de un modelo de crecimiento mundial basado en la globalización de las actividades económicas" (51) y que durante la época de Menem, "[d]e manera específica, en la Argentina la acelerada articulación entre lo local y lo global se produjo a partir de la apertura a la inversión extranjera” (52). Svampa también nota el crecimiento del fenómeno: "para el caso del Gran Buenos Aires, en 1994 sólo había 1.450 familias asentadas en este tipo de urbanizaciones; en 1996, cuatro mil. En agosto de 2000, el número de familias llegaba a 13.500" (57). Este fenómeno sigue creciendo ya que el country Nordelta, solamente un proyecto cuando Svampa publicó su estudio en 2001, contaba ya en 2010 con una población de unos 14.000 habitantes ("Primera"). La vida en los countries pasa del análisis sociológico a la literatura y al cine cuando Claudia Piñeiro publica Las viudas de los jueves (2005), Premio Clarín-Alfaguara de ese año que se convierte en un bestseller $y$ en 2009 el director Marcelo Piñeyro lleva la novela a la pantalla.' El título de la novela viene de una reunión semanal en que las mujeres van solas a comer en un restaurante mientras sus maridos juegan a las cartas.

Las viudas de los jueves tiene importancia dentro de la producción cultural argentina de la primera década del Siglo XXI. Es parte de lo que María Cristina Pons llama el "boom cultural que se da a pesar de la crisis, o en respuesta a ella" y ella opina que "en muchos casos la producción cultural argentina de estos últimos años constituye un fenómeno de resistencia cultural” (n.p.). Un análisis del texto fílmico teniendo en mente "the sociology and aesthetics of adaptation" (Andrew 458) nos permite demostrar cómo el director utiliza elementos del lenguaje cinematográfico para enfatizar temas como el materialismo, la avaricia, o la hipocresía de los personajes; y que incorpora 
cambios en la narración - en la película hay un mayor énfasis en la idea de la muerte y en la violencia relacionada con el sexo-con el fin de subrayar los efectos a veces ocultos del fracaso de la política del neoliberalismo, el cual va más allá de la dicotomía de “'exitosos' o 'perdedores.'” Así, basándose en una obra única sobre los countries, logra una excelente narración fílmica que indaga sobre aspectos importantes de la cultura argentina de principios del siglo XXI.

La acción ocurre en el country ficticio "Los Altos de la Cascada" y la autora advierte al principio de la novela que "[t]odos los personajes y situaciones narradas en esta novela son fruto de la imaginación, y cualquier parecido con la realidad es mera coincidencia" (10). Esta declaración resulta ser irónica, sin embargo, visto que, como Hugo Hortiguera observa, "[e]n efecto, muchos de los detalles que se describen podrían ser leídos a contraluz de las noticias periodísticas que circulaban por esos años sobre algunos casos indescifrables que habían ocurrido en esos barrios cerrados de la periferia porteña" y "la película no desaprovechó la publicidad que la conmoción de todos estos asesinatos misteriosos reales venía produciendo en el público en general” (116).

La obra de Claudia Piñeiro es una novela coral en que cada capítulo se concentra en un personaje o una pareja y la voz narrativa va alternando entre primera persona (la narradora, que a veces usa la primera persona plural, es Mavi, una agente inmobiliaria) y una tercera persona omnisciente. Según Raso, "[e]। relato cambia de narrador en cada capítulo, pero las que narran son, casi siempre, mujeres" (29) y son "distintas voces narradoras que configuran el 'nosotros' de esa comunidad" (30), o sea, "[d] iferentes voces que se van entrelazando para construir la imagen del country" (31). La narración fílmica se concentra en cuatro parejas: la agente inmobiliaria Mavi (Gabriela Toscano), y su marido Ronnie (Leonardo Sbaraglia), quien no trabaja actualmente; el Tano (Pablo Echarri), gerente de una multinacional holandesa y Teresa (Ana Celentano); Martín (Ernesto Alterio) y Lala (Gloria Carrá); Gustavo (Juan Diego 
Botto) y Carla (Juana Viale). También son importantes Juan (Camilo Cuello Vitale), el hijo de Mavi, y Trina (Romina en la novela; Vera Spinetta), la hija de Martín y Lala.

Como un country es una comunidad cerrada, solo se permite entrar a los residentes y las personas que trabajan allí. El hecho de usar este anglicismo representa cierto esnobismo, manifestado también en el mayor uso del inglés en la película con respecto a la novela. Raso observa que en la novela hay una división de espacios (country/periferia, adentro/afuera) (26). Para Hortiguera, esta narración parece "apropiarse de los términos de la dicotomía sarmentina-siempre latente en la cosmovisión argentina-para exteriorizar una serie de imaginarios de la degradación que se extienden al seno mismo de la ciudad, declinación que ya no es percibida como una forma excepcional y transitoria, sino definitiva" (14). En la primera escena del film, cuando el auto de Mavi entra al barrio privado, tiene que pasar por el portón con guardia y un aviso que reza "Prohibido el acceso a personas ajenas al country," lo cual pone de manifiesto esta división desde el primer momento. Así, vemos que hay una segregación total en la novela entre los residentes del country y los del pueblo contiguo, Santa María de los Tigrecitos (98), solamente identificado como "la villa" en la película y que se asocia con el crimen (en particular la droga), especialmente en la vida de Trina. Este espacio latente figura en la vida Trina cuando anuncia a su padre que va "a las villas" y él la llama "loca" (47:58). Con un sarcasmo que forma parte de la emasculación del padre, ella replica: "Te gusta el turismo de aventuras. Es lo mismo, pero es gratis" (48:02) y a pesar de la prohibición de su padre, ella sale y le espeta: "Nadie te escucha” (48:08). Ella le dice a Juan: "Estuve afuera. Afuera de verdad donde están los monstruos de verdad. ¿Dónde crees que conseguí esto?” (32:36-40), mostrándole un paquete de marihuana. Su ironía y su actitud abierta hacia la villa representan una dicotomía generacional que se verá también en la temática sexual. 
Para los otros residentes del country, es como si ese espacio no existiera y esto se manifiesta en el hecho de que solamente vemos la villa una vez en el film. Esto ocurre cuando Trina deja dinero para la droga detrás de un ladrillo y se encuentra con un guardia del country que se la facilita; con una grúa vertical por encima de la muralla que protege el country, vemos la villa al fondo. Para la gente del country, el espacio afuera representa la barbarie o que los que viven allí son animales como es evidente en la pregunta que hace Lala: “¿Qué pasa si la gente de la villa sale en estampida?” (1:30:11).

En principio el country se presenta como un lugar edénico. Cuando Mavi trata de venderle una casa a Gustavo, lo presenta como un ideal, diciendo que vivir allí "[e]s como estar en el paraíso" (14:07). Y su creación del mito continúa cuando conoce a Carla y comenta: "Somos como una gran familia. Esto es parte de su encanto" (16:26-28). Sin embargo, este mito poco a poco se desmorona. ${ }^{2}$ Este proceso se evidencia también al nivel lingüístico con las palabras que se usan para hablar de la vida allí. En una comida de los jueves, cuando las mujeres se quejan de sus hijos, Lala responde a Teresa con el mismo mito paradisíaco: "Vivís en un paraíso. Tus hijos te adoran, tu marido es un tipazo. La gente normal no es como vos, la gente normal sufre, siente, tiene problemas, ¿viste?” (1:33:41-50). Pero Teresa se levanta y va al baño donde se revela que su vida no es como los demás la perciben al quejarse: "Nunca me preguntan cómo estoy. [...] Piensan que no tengo necesidades, problemas" (1:38:32), y luego besa a Carla, rompiendo así la imagen de la esposa feliz. En una merienda, Mavi se queja de que su hijo no se integra y Lala dice: "Este lugar es una selva," (24:57). Este aspecto nos conecta con la interpretación que Carolina Rocha tiene de la novela: "The males of the community compete constantly with each other, struggling to retain (or reluctantly granting) superiority through sports or card games" (126). Más tarde, cuando el Tano y Teresa patrocinan la fiesta de Navidad para los residentes del country, ella habla del placer de compartirla con la comunidad, pero Lala le dice a Martín, 
“Bla, bla, bla... hipocresía, sentimentalismo" (1:13:19-20), lo cual desmitifica la bondad de los anfitriones y constituye otro paso en el desmoronamiento del concepto del country como paraíso.

Aunque las casas y los autos que tienen los residentes indican un alto nivel de ingresos, este nivel resulta ser precario. El guion enfatiza esta precariedad en dos escenas originales. En una conversación entre el Tano y Carla, él admite, "A veces me despierto y me pregunto dónde estoy. Todo parece tan perfecto, tan irreal. Tengo miedo de que alguien diga, 'Ya está, Tano. Se acabó ... Al transporte público. Al negocio de tu viejo" (55:04-26). Carla también percibe la falsedad del paraíso: "A veces siento que no soy de acá, que no es mi lugar" y el símil que usa para el country - "Es como un escondite"-y el hecho de que tiene miedo "de que me denuncien" (55:35-53), revela que sutilmente asocia la vida del country con el crimen. En la escena del entierro de la madre de Luisina (que no existe en la obra original), los comentarios bruscos del Tano representan los problemas de esta sociedad de los countries. Como el Tano se aprovechó de la póliza de seguros de una mujer difunta, la hija de la fallecida no quiere verlo. El Tano les echa en cara que "[n]adie quiere pagar el coste de vida aquí... [Creen] que están limpios ustedes que señalan a la gente con el dedo? Ustedes están hasta acá [tocando la barbilla] como yo" (1:20:55-1:21:07). Así, la hipocresía y la corrupción son concomitantes con toda la sociedad de este barrio privado.

A través de la importancia que se da al dinero, el materialismo aparece como otro elemento inherente a los habitantes de este barrio privado. La mujer de Sergio está pasando por un momento difícil por la enfermedad de su madre, y el Tano le recomienda, “Comprale otro auto, Ilevala a Europa” (09:41-43). Como observa James Griesse en cuanto a los personajes de la novela, "Their class identity is largely based on their level of consumption, and... the objects of their consumption function as signs that indicate their class status and mark their differences from other classes" (57). En la adaptación cinematográfica, 
los elementos de la puesta en escena, especialmente las casas lujosas (con sus piletas) y los autos sirven para marcar sus valores de estatus social.

Marcelo Piñeyro también usa el espejo múltiples veces como parte de la puesta en escena para subrayar los problemas internos de los personajes; como notan J. A. Place y L. S. Peterson, en el cine, "mirror reflections, beyond their symbolic representations of fragmented ego or idealized image, sometime assume ominous and foreboding qualities solely because they are so compositionally prominent" (335). El Tano y Sergio se preparan para la fiesta de cumpleaños de Teresa, y el Tano dice que antes creía en Dios, luego en la democracia, pero añade, “¿Sabés en lo que creo ahora? En la guita. Verdadero idioma internacional. Cuando tenés plata en el bolsillo te entienden en todas partes" (09:07-15). Pero al final de este soliloquio, la cámara hace un travelling hacia atrás y nos damos cuenta que todo ese tiempo estábamos mirando su imagen en el espejo, lo cual connota la artificialidad, la hipocresía y la falsedad de que lo que dice. Para el Tano, sin embargo, el espejo es un medio de autoafirmación y del sentido de merecimiento; le dice a Sergio: "Cada vez que te mirás en el espejo, preguntate, ‘'No me lo merezco todo?’” (09:57-58). Así, el espejo subraya los aspectos negativos de este personaje: el egoísmo, la codicia, y la superficialidad, todo con una sensación de aprensión.

Otros ejemplos de espejos en la puesta en escena a lo largo de la película hacen hincapié en la hipocresía o división interna de los personajes. Cuando entra Martín y el Tano le pregunta si le ha contado a su mujer que no tiene trabajo, aquel se mira en el espejo, una respuesta que indica su hipocresía al ocultar la verdad. Más tarde, cuando los hombres juegan al póker, los vemos primero reflejados en el espejo, lo cual también indica los problemas interiores que tienen, especialmente la hipocresía en cuanto a su verdadero bienestar. En la funeraria, cuando entra Carla, ella y Teresa se abrazan, y Teresa ve el reflejo de ambas en el vidrio de un cuadro en que unos perros cazan ciervos, símbolo de las relaciones en el country. Más tarde, ellas se encuentran delante 
del espejo del baño en el restaurante, y allí Teresa manifiesta abiertamente sus deseos lesbianos, besando a Carla; de nuevo el espejo refleja la duplicidad y la hipocresía. Por último, al final de la narración, al salir del country, llegan al portón, y con Ronnie en el asiento trasero, el guardia trata de disuadirles de salir, pero con el punto de vista de Mavi al volante, la imagen de Ronnie en el espejo retrovisor confirma la decisión de seguir adelante.

El director también usa un foco superficial en varias ocasiones para destacar los problemas individuales o sociales: la falta de escrúpulos, la hipocresía y el encubrimiento de la verdad. Cuando el Tano explica su plan para estafar a gente de dinero con seguros de vida, Ronnie está al fondo al lado de la pileta y dice, "Qué sublime Tano. Cómo desnudás la naturaleza del sistema que es predatorio, por supuesto. Es capitalismo puro. ¿Qué pasaría si no hubiera más gente a que chuparles la sangre?" (38:35-:48). El hecho de estar fuera de foco (con el foco superficial sobre el Tano) implica que Ronnie no entra en el sistema de valores del Tano. En otra escena, Martín, quien ha perdido su empleo sin que lo sepa su mujer, se lava los dientes en primer plano y al fondo, Lala le critica, "Tenés que hacerte notar" (52:07). Al estar ella fuera de foco, el director subraya su ignorancia de la situación verdadera de su marido. La escena termina con un gesto significativo: Martín escupe, lo cual representa su rechazo a su mujer y a todo el sistema. Finalmente, en una escena hacia el final de la película, Ronnie y su esposa están en su cocina; éste sabe que no fue un accidente, que los hombres se suicidaron, y piensa que tiene una obligación moral de decir la verdad a sus esposas. El enfoque superficial cuando el dice, "Lo tengo que decir," (1:47:58) con Mavi (que está en contra de decirlo) al fondo, fuera de foco, le da cierto peso moral a Ronnie.

Desde el comienzo, los problemas económicos tienen un impacto en las vidas de los personajes, sobre todo la de Martín, quien fue despedido. Su problema financiero se manifiesta simbólicamente de forma física: cuando hace cuentas y comprende que está en un aprieto económico, le sangra la 
nariz. Y esto ocurre otra vez cuando está manejando su minivan (un vehículo que representa su supuesto bienestar económico) y tiene que salir de la carretera: no poder llegar directamente a casa simboliza su incapacidad de pagar la mansión lujosa que habita. Aunque en la novela es evidente que su mujer se da cuenta de la situación laboral de Martín (142), en la película, el esposo oculta con éxito esta verdad dolorosa. Por consiguiente, el problema más grande que tiene Martín es la falta de comunicación con su pareja. ${ }^{3}$ En la escena al principio de la película, cuando Martín dice a Tano que tuvo "[e]ntrevistas nada más," implicando que no aún tiene trabajo, el Tano sugiere, "Lala podría darte una mano en todo esto [...]. ¿Todavía no le dijiste nada?" (10:46-54). Esta falta de comunicación culmina en una escena que empieza con un primer plano de Martín, sentado en su salón con luces navideñas al fondo que subrayan la supuesta felicidad de la familia. Martín empieza diciendo, "Tenía que haberte dicho antes..." (1:23:44) Luego echa la culpa a la situación macroeconómica y al país en que viven: "No hice nada mal, Lala. Lo que se cayó fue el país... vendemos la casa... dejame terminar [...] ir a Miami. Escojamos un país serio. Nosotros nos merecemos eso, ¿no?” (1:24:08-1:25:13). Pero la cámara empieza un travelling hacia atrás, y nos damos cuenta de que no hay nadie en el salón y que Martín habla al vacío. La repetición de su frase, “Tenía que habértelo dicho antes" (1:25:56, 1:26:06) dirigida a un sillón vacío intensifica la vergüenza y la hipocresía de este personaje.

En la película los problemas no son solamente financieros. Así, por ejemplo, mientras que en la novela los problemas del Tano surgen cuando pierde su trabajo en la compañía holandesa (171), en la película, predominan sus problemas de pareja. Se da mucho más énfasis al sexo en la película que en la novela y casi siempre tiene connotaciones negativas. El sexo en el film es mayormente otro síntoma del fracaso y, así, desmiente el concepto de los "exitosos." Esto se ve especialmente en la relación entre el Tano y Teresa. La primera vez que hay un episodio romántico entre ellos, Teresa se encuentra en 
su camisón cepillándose del pelo delante de un espejo. El Tano entra, se quita la camisa; luego se acerca a Teresa y le toca el tirante de su camisón, un gesto que se va a repetir en otra escena más tarde con un nuevo significado. Teresa, sin embargo, no muestra mucho interés y empieza a hablar de una pareja que se compró una casa en Montreal para que puedan esquiar todo el año. Tano le quita el cepillo (un gesto de dominación) y la besa. El corte al primer plano de Teresa de perfil demuestra lo mal que va su relación sexual cuando ella se queja: “Despacio, bruto" (29:16), y luego en tercer plano vemos que Tano le practica sexo oral, pero de forma inepta. La insatisfacción de Teresa parece empujarla hacia otros deseos.

De hecho, los deseos lesbianos de Teresa se hacen cada vez más evidentes. Si bien en la novela, la posible relación lesbiana es entre Carmen Insúa y su mucama, Gabina,-_éste es un ejemplo de cómo la película capta el espíritu de la novela cambiando la narración original-en la película encontramos la siguiente escena: Cuando Carla y Teresa visitan el viejo establo, de repente salen unos cuervos, lo cual es un presagio de algo negativo; Teresa se asusta y comenta, "Menos mal que me agarraste" (1:05:45). Luego le quita las gafas a Carla y le toca la frente. El primer plano de la cara de Teresa manifiesta deseo sexual. Más tarde, Teresa se encuentra en su estudio usando su computadora; en una foto, borra la imagen del Tano y los demás y mueve la imagen de Carla al lado de la suya. Al entrar su marido, vuelve a la imagen original para esconder este deseo latente. Luego el Tano le baja el tirante de su camisón (igual que hizo en la escena romántica anterior) y ella se la sube en un claro gesto de rechazo. El Tano pregunta, “¿Venís a dormir?” y ella contesta con una mentira: “Ahí voy" (1:12:01), y vuelve a borrar la imagen de su marido, poniendo la de Carla a su lado de nuevo. De esta manera, el borrado metafórico anticipa el borrado físico. Sus deseos lesbianos culminan en la escena en el baño del restaurante cuando Carla la sigue allí. En contraste con la vida perfecta que Lala pinta para Teresa, ésta se queja, “Piensan que no tengo necesidades, problemas, que yo 
no siento. Yo siento cosas, Carla" (1:38:43). El vestido que lleva Carla-rojo con amplio escote-subraya el elemento erótico de la escena. Teresa le toca el hombro y como Carla no reacciona de forma negativa, Teresa le besa los labios. Así, el deseo lesbiano destruye el mito de su matrimonio ideal.

En contraste con la novela, el sexo en la película es parte de la violencia del lugar. ${ }^{4}$ Cuando ven los fuegos artificiales, Teresa advierte a Gustavo sobre su abuso doméstico hacia Carla: "Si la lastimás otra vez te vas a meter en problemas" (1:14:48-50). Cuando Carla vuelve a casa, Gustavo se acerca a ella y lo que empieza como un encuentro sexual se transforma en violencia, ya que él trata de estrangularla con su cinturón. Más tarde, Trina es víctima de una violación cuando el guardia que le suministra drogas la encuentra a solas en una casa en construcción; además, el agente sugiere que va a poder controlarla en el futuro porque tiene un video en el que ella aparece vendiendo droga y le declara, "Sos mi gata, sos mi esclava" (1:33:16-17). El único encuentro sexual positivo es entre Trina y Juan, una relación que ella inicia en el parque; después de su violación, Juan la consuela y ella declara al abrazarlo: "Quiero que te quedes conmigo. [...] Sos tan lindo, Juan, tan bueno.” (1:44:25-50). El sexo/ violencia es, pues, otro elemento sórdido que existe debajo de la fachada de la vida perfecta, con una única luz de esperanza puesta en la generación joven.

Aunque no hay en la novela ningún detective o policía como protagonista que investigue el asunto, la estructura de la obra de Piñeiro tiene elementos importantes en común con una novela de detectives. Según Victor Erlich este género es "a remarkably clear example of the crucial narrative principle of “deliberately impeded form'” (178), ya que el narrador retiene información para crear misterio y suspense. Hay un elemento de suspense, pero lo importante es el retrato de esta sociedad cerrada que ofrece la novela. En este sentido, la novela exhibe una estructura circular: al principio de la narración, tres hombres aparecen muertos en una pileta (23) y después se da una analepsis que describe los antecedentes de este evento hasta llegar otra vez al presente. 
Aunque el título de la narración sugiere la muerte, en la versión fílmica hay más énfasis en este tema desde el principio: durante los créditos del film, hay imágenes de los cadáveres flotando en la pileta durante 2 minutos, 54 segundos, con encuadres que varían desde un tercer plano a un primer plano. Por consiguiente, sabemos desde el primer momento que hay víctimas y hacia el final de la novela, Mavi se entera de la muerte de los hombres, que fueron electrocutados (288).

Aunque la película mantiene esta estructura circular de la novela, con la escena repetida en que Mavi lleva a Ronnie al hospital, el director efectúa un cambio importante en la estructura narrativa al incorporar cuatro saltos temporales que nos llevan al presente, siempre haciendo hincapié en la muerte. El primer salto ocurre después de una pesadilla de Gustavo en la que piensa matar a su esposa, preparando así el terreno para el salto en que Mavi acompaña a Teresa en una funeraria para seleccionar ataúdes. En ese segundo salto, siguen allí y el empleado de la funeraria le pide a Teresa que firme un documento y entran Carla y Lala. En el tercero, El Tano, sentado en un sillón, está leyendo un diario mientras bebe whiskey con la música de "Que reste-t-il de nos amours?" (59:35-46) de Charles Trenet al fondo (cuya letra capta la esencia de su relación con Teresa). Se levanta y casi pisa el diario en el suelo; vemos que estaba marcando los anuncios de defunciones, parte de su plan fraudulento sobre la llamada viaticación de los seguros. Esta referencia a la muerte provoca el cuarto salto temporal, con el corte a primer plano de la cara de Tano muerto con algodón en la nariz, pero la música francesa continúa mientras le aplican maquillaje al cadáver. Este puente sonoro borra la línea entre la vida y la muerte de los personajes. En este último salto temporal, el color morado de las vestiduras del cura en la capilla para el funeral se ve reflejado en un ataúd.

Además de estos saltos temporales, hay otros elementos que subrayan el tema de la muerte a lo largo de la película. Al principio hay una fiesta para el 
cumpleaños de Teresa, y todos se visten de blanco. Lala dice que "en la India el blanco es color de la muerte," pero el Tano replica, "Porque la muerte es pureza allá, no mugre como acá” (12:33-35), lo cual sugiere que su propia muerte va a ser causada por problemas. Luego, cuando Gustavo se despierta de su pesadilla, Carla pregunta qué le pasa, y su marido contesta, "Soñé que te mataba" (42:07). Quiere hacer una cita con su terapeuta, lo que sirve de sinécdoque para la sociedad argentina, ya que la Argentina es el país con más terapeutas en el mundo (Romero). Más tarde, Gustavo trata de estrangular a Carla con el cinturón de ella y termina llorando en sus brazos. Esto representa un cambio respecto a la segunda escena de abuso doméstico de la narración original cuando "Gustavo, con el puño cerrado, le acertó un golpe en la mandíbula" (237), mientras intensifica los problemas psicológicos del marido y los sentimientos conflictivos de la mujer.

El tema de la muerte también surge sutilmente en comentarios a lo largo del film. Cuando Teresa está usando su computadora, el Tano le dice: "La madre de Luisina está muy mal” (1:12:13) a causa de la enfermedad terminal de su madre. En la escena en que el Tano le practica sexo oral a Teresa, ella dice: "Debería matarte, pero te veo allí abajo..." (29:30). Después de que Carla sufre un incidente de abuso doméstico, Teresa le ofrece píldoras (Tano había descubierto Prozac en su bolso), pero Carla contesta: "No quiero soporíficos ... Me hacen sentir muerta por dentro, medio zombie" (1:06:53-59). Y en un partido de tenis, Gustavo y el Tano son compañeros y cuando aquél falla mucho, éste le aconseja que imagine a los otros jugadores como muertos 1:01:40). Y hacia el final, cuando Ronnie vuelve a casa y pregunta a su esposa si se sentiría aliviada si él no estuviera, Mavi replica: "Si estás pensando en deshacerte de mí, te mato" (1:46:21). Sin embargo, el momento en el que se pone mayor énfasis sobre la muerte tiene lugar en la conversación sobre la misma antes del suicidio al lado de la pileta del Tano y sus tres amigos. Estas referencias constantes a la muerte nos llevan inexorablemente a la tragedia 
final. Asimismo, con ironía dramática, Marcelo Piñeyro conecta el tema de la muerte con la hipocresía de la sociedad en la escena al final de la película en la que Ronnie revela la verdad a las tres viudas. Teresa, sentada en el sofá entre Carla y Lala, frente a Ronnie, contesta a sus acusaciones. Durante cada declaración retórica que hace Teresa-que Tano no la quería, que Gustavo no quería a Carla y que Martín no quiso admitir que ya no tenía empleo-la cámara se enfoca en cada mujer en cuestión, destacando la hipocresía de la situación.

Los problemas macroeconómicos del país aparecen de un modo más marcado en la versión fílmica de Las viudas, ya que Piñeyro utiliza imágenes de archivo, que pone en las noticias en la televisión, para captar el caos callejero. En dos ocasiones, Ronnie mira las noticias y ve saqueos, policías a caballo y escuchamos el informe de que 27 personas fueron asesinadas por la policía, con el sonido de sirenas subrayando el ambiente amenazante. Estos problemas afectan directamente a los personajes: mientras el empleado de la funeraria atiende a Teresa y Mavi, recibe una llamada en la que habla de las cuentas congeladas. Martín se queja de que quería mantener su dinero en el país por los intereses altos, pero ya es tarde. En una de las pocas escenas de la película que transcurren afuera del country, hay una cola de autos en una gasolinera y se escucha en la radio un informe sobre los problemas del país, mientras escuchamos sirenas al fondo y vemos que Martín está en atrapado en el atasco, lo cual es tanto metafórico como físico.

El tema de las apariencias es importante tanto en la novela como en la película. Griesse observa que "Piñeiro's novel uses the broad theme of appearances to question consumption as a basis for citizenship and to critique the neoliberal turn in Argentina as a solid foundation for economic modernization and prosperity" (57) y que "the novel's implicit critique of consumerism nor the idea that neoliberal capitalism offered merely a superficial illusion of prosperity without a solid foundation, both of which are 
tied to the theme of appearances in the novel" (59). En la película, cuando Mavi y Ronnie van a la casa de Carla y Gustavo, Mavi le comenta a su marido: “Las apariencias engañan" (15:18). Así el guion capta este tema importante en una frase escueta.

Es importante señalar que el final de la película tiene un cambio importante con respecto a la obra original. En la novela, Juan ofrece una prueba de lo que ocurrió en la pileta: él y Romina solían espiar y sacar videos de los vecinos, y muestra el video a sus padres de los últimos momentos de vida del Tano y sus amigos: Gustavo no quiso suicidarse y el Tano lo tiró a la pileta y, así, en realidad lo mató en el momento del suicidio (314-15). Para Rocha, "Not surprisingly, the two characters who manage to see the domestic tensions, social prejudices and general xenophobia of the gate community's members are its two disaffected, maladjusted, and marginalized teenagers" (127). Cuando Juan sugiere que vayan a la policía, Ronnie tiene dudas y no sabe qué hacer, pero su hijo dice “'¿No sabés? Hay veces en que uno sí o sí tiene que saber" (316). Se van en su auto y el final abierto da la impresión de que van a salir para denunciar el crimen. En un sentido, en la novela, Juan resulta ser el "detective," puesto que "resuelve" el crimen. Así, se sigue la pauta del género detectivesco contemporáneo, en el que, como calcula Richard Alewy, solo entre el diez y el veinte por ciento de los sabuesos son detectives oficiales (67). ${ }^{5}$ El final implícito cumple con otro elemento importante del género, ya que como afirma Dennis Porter, la narración tradicional de detectives "moves from mystery to solution and from crime to punishment or, if not to punishment, at least to arrest" (85) y añade: "The classic structuring question is always 'Whodunit' and secondarily, how will justice be done" (125). En la película, no hay ninguna referencia a la prueba del crimen que tiene Juan, aunque éste sigue teniendo un peso moral cuando dice, “'Vámonos de acá. Lo hacemos lo antes posible. Vendé la casa, Ma. No tenemos nada que ver con este lugar ni con esta gente" (1:51:03-11). Así, el abandono del country es más 
definitivo en la película sin el peso moral del original, visto que no hay ninguna intención de denunciar el crimen a las autoridades.

Al examinar cualquier adaptación cinematográfica, hay que considerar la importancia de "the contact between the social, political and cultural contexts" de los dos textos (Faulkner 7). Si bien la novela de Piñeiro refleja los problemas socioeconómicos y psicológicos que manifiestan los informes sociológicos de Svampa y Castelo sobre los countries, la adaptación cinematográfica de Piñeyro los subraya, reflejando los problemas económicos argentinos que continúan en el año en que se rueda la película (Gambina). Esto y el hecho de contar la película con más de medio millón de espectadores-el doble de los lectores que compraron el libro-hace que el film de Piñeyro sea aún más relevante para la sociedad argentina. ${ }^{6}$ La cuestión económica también tiene que ver con la producción de la película: es una coproducción entre España (65\%) y Argentina (35\%) ("Largometrajes"), rodada en countries argentinos y en la Ciudad de la Luz en Alicante. Estos porcentajes indican la importancia de las coproducciones en el cine argentino actual.

La explosión del neoliberalismo tuvo un efecto profundo en la sociedad argentina. Sebastián P. Salvia nota que "las reformas neoliberales generaron el deterioro de las condiciones de vida de amplios sectores de la clase trabajadora, que se tradujo en el aumento del desempleo y una mayor desigualdad en la distribución del ingreso" y también "generaron diversas formas de protesta social," especialmente "una alta conflictividad sindical" (110, 116), algo que Piñeyro representa al final de la película. Sin embargo, en Las viudas de los jueves vemos que las clases altas también fueron afectadas. Las reseñas de la película en los dos diarios más importantes del país, La Nación y Clarín, destacan la importancia de esta película de denuncia social, considerándola una "[m]etáfora sobre el resquebrajamiento económico, social y moral que puso fin a la década de los 90" (López) y "un fresco social sobre el ascenso y caída de nuevos ricos, a lo largo de los ‘90, encerrados en el paraíso/prisión 
de un country" (Frías). El análisis de la película realizado nos permite un nuevo entendimiento de este fenómeno, al destacar los cambios en la adaptación fílmica que hacen hincapié en la hipocresía (especialmente con el espejo como parte de la mise-en-scène), la insatisfacción o la violencia sexual y la muerte, todo lo cual manifiesta plenamente los síntomas de esta explosión del neoliberalismo. La adaptación cinematográfica de Las viudas de los jueves demuestra que efectivamente, el paraíso de los countries argentinos realmente puede ser un paraíso perdido.

\section{Notas}

1 Hay otras aproximaciones fílmicas a la temática de los countries en la Argentina: Una semana solos (2008) de Celina Murga y La ciudad que huye (2006) de Lucrecia Martel.

2 Para los que vieron el trailer oficial de la película, este proceso de desmoronamiento se sintetiza en unas frases escuetas: "Una vida idílica / Tres muertes / Una verdad que hay que silenciar / El paraíso está al punto de estallar / El lado oscuro de una vida perfecta" (“Trailer”), frases que también nos permiten vislumbrar la temática del film.

3 Para Hortiguera, la novela tiene "personajes caracterizados por su opacidad, su insinceridad y su imposibilidad por entablar una comunicación franca con el otro, aun dentro de sus propias fronteras" (120).

4 Carolina Rocha mantiene que la novela es "an illustration of the correlation between systemic violence and social exclusion” (124), y la versión cinematográfica subraya este concepto.

5 Para Raso la novela es un "relato policial" y dice que "Romina y Juani son los detectives (o testigos) involuntarios del suicidio y crimen" (33).

6 La película tuvo 522.004 espectadores en Argentina (Anuario de la industria del cine 2010) y 67.629 en España (Boletín). Al cumplir su décimo aniversario (2015), el libro había vendido unos 250.000 ejemplares (Luján Picabea). Después del éxito de esta película, dos obras más de Piñeiro fueron llevadas a la pantalla: Betibú de Miguel Cohan (2014) y Tuya de Edgardo González Amer (2015).

\section{Obras citadas}


Alewy, Richard. "The Origin of the Detective Novel." The Poetics of Murder. Detective Fiction and Literary Theory, editado por Glenn W. Most y William W. Stowe, Harcourt Brace Jovanovich, 1983, pp. 62-78.

Andrew, J. Dudley. Concepts in Film Theory. Oxford UP, 1984.

Anuario de la industria de cine 2010. INCAA, www.incaa.gov.ar/wp-content/ uploads/2018/10/Anuario 2010.pdf Fecha de acceso: 3 ago. 2015.

Boletín informativo 2010. Instituto de la Cinematografía y de las Artes Audiovisuales Ministerio de Cultura, www.culturaydeporte.gob.es/dam/jcr:3d8f1822-d5a0-4404a8de-7321a238a57c/32-indice-largos.pdf Fecha de acceso: 4 ago. 2015.

Castelo, Carla. Vidas perfectas: Los countries por dentro. Sudamericana, 2007.

Erlich, Victor. Russian Formalism: History-Doctrine. Mouton, 1955.

Faulkner, Sally. Literary Adaptations in Spanish Cinema. Tamesis, 2004.

Frías, Miguel. "Ascenso y caída en el country." Clarín, 10 sep. 2009, www.clarin. com/ediciones-anteriores/ascenso-caida-country_0_Bk9bYaOATFx.html Fecha de acceso: 7 mar. 2017.

Gambina, Julio C. "La Economía Argentina durante la crisis económica mundial.” El blog de Julio C. Gambina, mayo 2009, http://juliogambina.blogspot.com/2009/05/ la-economia-argentina-durante-la-crisis.html Fecha de acceso: 23 jul. 2020.

Griesse, James. “Economic Crisis and Identity in Neoliberal Argentina: Claudia Piñeiro's Las viudas de los jueves." The Latin Americanist, vol. 57, no. 4, 2013, pp. 57-71, http://doi.org/10.1111/tla.12009 Fecha de acceso: 31 ene. 2014.

Hortiguera, Hugo. "Después de la globalización, la destrucción de lo social en dos filmes argentinos: Las viudas de los jueves y Carancho." Letras Hispanas, vol. 8, no. 1, Spring 2012, pp. 112-127, http://gato-docs.its.txstate.edu/jcr:73bf0177-ee9c469e-9d1f-d48a2e3e8a05/H.Hortiguera.pdf Fecha de acceso: 29 ene. 2014.

"Largometrajes realizados en coproducción con otros países." Boletín informativo 2010. Anuario de cine. Año 2010. Instituto de la Cinematografía y de las Artes Audiovisuales. www.culturaydeporte.gob.es/dam/jcr:092b2684-6e15-4387-8bc9ffc6c68b75da/05-largos-coproducidos.pdf. Fecha de acceso: 4 ago. 2015.

López, Fernando. “Dinero, trivialidad y vidas vacías." La Nación, 10 sep. 2009. www. lanacion.com.ar/espectaculos/cine/dinero-trivialidad-y-vidas-vacias-nid1172611/ Fecha de acceso: 23 jul. 2020.

Luján Picabea, María. “Aniversario: Las viudas de los jueves cumplió una década.” 
Clarín, 25 dic. 2015, www.clarin.com/literatura/las_viudas_de_los_jueves-claudia pineiro-una decada 0 SJBejhR wml.html Fecha de acceso: 7 mar. 2017.

Piñeiro, Claudia. Las viudas de los jueves. Clarín-Aguilar, 2005.

Place, J. A. y L. S. Peterson. "Some Visual Motifs of Film Noir." Movies and Methods, Vol. I, editado por Bill Nichols, U California P, 1976, pp. 325-38.

Pons, María Cristina. "Neoliberalismo y producción cultural: Reflexiones sobre la 'explosión cultural' argentina post-crisis del 2001.” Espéculo, vol. 41, marzo-junio 2009, http://webs.ucm.es/info/especulo/numero41/neolibe2.html Fecha de acceso: 8 mar. 2017.

Porter, Dennis. The Pursuit of Crime: Art and Ideology in Detective Fiction, Yale UP, 1981.

“Primera vez de Nordelta, el gigantesco barrio privado." Clarín, 28 oct. 2010, www. clarin.com/sociedad/Primera-Nordelta-gigantesco-barrio-privado 0 B1kfAQo6wml Fecha de acceso: 23 jul. 2020.

Raso, Laura Elina. "El edén cercado: Segregación espacial y construcción de identidades en las urbanizaciones privadas." Tópicos del seminario, vol. 24, 2010, pp. 25-39, http://href.scielo.org/4hjg55 Fecha de acceso: 17 jun. 2014.

Rocha, Carolina. "Systemic Violence in Claudia Piñeiro’s Las viudas de los jueves." Arizona Journal of Hispanic Cultural Studies, vol. 15, 2011, pp. 123-29.

Salvia, Sebastián P. "La caída de la Alianza: Neoliberalismo, conflicto social y crisis política en Argentina." Colombia Internacional, vol. 84, mayo-agosto 2015, pp. 107-38, http://dx.doi.org/10.7440/colombiaint84.2015.04 Fecha de acceso: 7 mar. 2017.

Svampa, Maristella. Los que ganaron: La vida en los countries y barrios privados. Biblos, 2001.

"Trailer oficial de Las viudas de los jueves." 24 ago. 2009, www.youtube.com/ watch?v=IGOF-h5IKVQ Fecha de acceso: 8 mayo 2020.

Las viudas de los jueves. Dirigido por Marcelo Piñeyro. Castafiore Films / Haddock Films / Televisión Federal / Tornasol Films, 2009, DVD. 